\title{
Comparison of Different Clustering Algorithms to Secured VANETs Communication
}

\author{
Prashant Kumar Shrivastava ${ }^{1}$, Dr. L. K. Vishwamitra ${ }^{2}$ \\ 1P.H.D. Scholar C.S.E Department, Oriental University Indore, India \\ ${ }^{2}$ Professor C.S.E Department, Oriental University Indore, India
}

\begin{abstract}
Article Info

Volume 7, Issue 6

Page Number: 59-75

Publication Issue :

November-December-2021

\section{Article History}

Accepted : 05 Nov 2021

Published : 20 Nov 2021

ITS (Intelligent Transportation Systems) are growing increasingly popular because of the necessity for superior cyber-physical systems and comfort applications and services required for usage in autonomous vehicles. There are two types of Vehicular Ad-Hoc Networks (VANETs) that are vital to ITS: V2I (Vehicle-to-Infrastructure) and V2V (Vehicle-to-Vehicle). VANETs are a new technology with several potential uses in the ITS. It comprises smart vehicles and roadside equipment that connect over open-access wireless networks. An attacker may disrupt vehicular communication which can lead to potentially life-threatening scenarios because of the significant expansion in the number of vehicles in use today. VANETs must use robust security and authentication procedures to provide safe vehicular communication. This paper provides a comprehensive analysis ofthe VANET system including its characteristics and challenges. There is a concept of data dissemination that has been provided in brief. Clustering is the most important topic in VANET that is used to cluster the vehicles to secure and safely message transmission over the network. There is a taxonomy of clustering techniques has provided in a detailed manner. Besides, it has also shown the comparison of different clustering parameters-based mechanisms and MAC protocols in VANET.

Keywords: Terms-Intelligent Transportation System, VANETs Characteristics \& challenges, Data dissemination, Clustering, Security, MAC protocols.
\end{abstract}

\section{INTRODUCTION}

Intelligent Transportation Systems (ITS) are made up of a network of vehicles that exchange data wirelessly. A vehicle's location, speed, and direction may be broadcast to all other cars within range using sensors and GPS technology. Safety messages are sent between vehicles to enhance road safety \& save lives from accidents in a dangerous vehicular environment. Status messages and safety messages are the two most common forms of data sent between vehicles [1]. The status message provides information on the vehicle's speed, acceleration, and position. All of the vehicles get periodic status messages, which are also known as 
beacon messages. There are pre-crash and post-crash notifications, as well as environmental and road risks, in the message.

VANET is a specific type of MANET(Mobile Ad-hoc Network) that allows vehicles to share info without the support of permanent structures such as base stations or access points [2]. In VANET, mobility of vehicles results in dynamic variations to network architecture, that have a direct effect on the network's performance metrics like throughput, transmission latency, as well as packet loss rate. The study on topology \& related routing procedures of VANET is based on reproducing actual traffic flow in a simulated environment.[3]. Thus, vehicular mobility modeling [4] has increasingly been a focus of VANET simulation research, intending to extract movement commonality of vehicle nodes to increase simulation's authenticity, ensuring that simulated findings can be applied to real-world deployments.

An emphasis is placed on the transmission of emergency messages between vehicles in this research report. For V2V and V2I communication, VANET employs DSRC at $5.9 \mathrm{GHz}$ [5]. All seven channels of DSRC may transmit data at a maximum rate of $27 \mathrm{Mbps}$ over a distance of 1000 meters. A $5 \mathrm{MHz}$ guard band separates the seven channels each operating at $10 \mathrm{MHz}$. All seven channels have one control channel \&the other 6 are service networks for non-safety or commercial purposes. Short-range wireless networks may be established using either a radio interface or an On-Board unit. So that no safetyrelated communications are missed, vehicles alternate between control channel \& service channel operation. To provide the driver with adequate time to respond to the issue, communications are prioritized according to the severity of the problem.

Crashing vehicles and other dangerous situations are given top attention in communications. Post-crash notice, road \& environmental concerns, and the status message that provides information on a vehicle's directions, speed \& location are given second \& least importance. The prototypeas well examines the effect of the concealed terminal issue, which is not stated in the existing VANET broadcasting scheme. It measures the impact of the concealed terminal issue using the packet delivery ratio. Roadside Unit (RSU) deployment in sparse traffic situations is explored to improve emergency message transmission performance by avoiding vehicle disengagement.

In VANET safety applications, providing an efficient and secure authentication method is a difficult problem. To meet their deadlines, these apps must respond to messages in a timely way. To protect the confidentiality of the communications sent, it is necessary to ensure that the information included in these messages is protected [6].

The design of this work is as follows: Section II offersa detailed description ofthe VANET system, its characteristics, and challenges with a briefing of data dissemination. Section III provides a descriptive overview ofthe clustering concept which is used in VANET, also displays the comparison among different works. After this, in section IV we provided a literature survey related work to VANET. Section V concluded the overall paper with some future scope for this work.

\section{Vehicular Ad hoc Network System,Characteristics and Challenges}

As its foundation is a network of vehicles, several nations are presently attempting to install VANETS to make this technology widely applied worldwide. All VANETS-based cars can communicate with each other using the same messages. Changes in location or proximity to another vehicle might cause these notifications to be shown in a different way for neighboring vehicles. You'll get alerts about your vehicle's current GPS position as well as information about its current direction and speed. The integrity of all of these communications must be maintained since they are all critical to the flow of information. There 
are no more accidents on the road because of the sharing of information between vehicles. VANETs' predictive nature makes it easy to cope with emergency scenarios. Having a traffic-free road has allowed people to better manage their time. Because VANETs function as an interconnected network, retailers and other businesses may simply distribute advertisements via them. The information might also be fabricated by attackers who gain illegal access. Having a nonrepudiation mechanism is essential in this situation. In addition to the safety of cars, VANETSs also guarantee the convenience of drivers and pedestrians on the road [7]. Safety characteristics include intrusion movement aid, road weather,blindspot warning, emergency electronic brake lights, forward collision warning, and left-turn help. Drivers might be alerted to their speed due to dynamic message signs. In the future, VANETS will be able to forecast which direction and how long drivers will have to wait at traffic signals. Another benefit of VANETS is dynamic transit operations \& ride sharing. In addition to communicating with other vehicles, VANETS allows your vehicle to interact with the driver as well. Any form of mishap may be avoided by activating an emergency alarm, which includes shaking of the seat and red indications on the indicator lights. Because the network has a huge number of nodes. Every node has to be verified and authenticated individually, which takes a lot of time. Accidents may occur if all nodes are unable to interact with each other at the same time[8]. There are more vehicles on the road, which means more bandwidth is needed for the signals network, which may lead to signal interference and other concerns. It is difficult to interact with all the vehicles in the network because of the decentralized approach. Attackers may make use of its networking capabilities. They can tamper with the communications or insert dangerous material. VANETs must be implemented safely. The system's security has been hampered by an increase in the variety of assaults that may be launched, due to advancements in technology. VANET security is primarily threatened by Denial-of-Service (DoS) attacks, floods, spamming, and malicious software. VANETs must be implemented quickly. As a matter of course, information must be sent on time. Even though VANETs are vulnerable to assaults such as jamming, which prevent radio waves from transmitting data, this is just one attack type. Malware injection may have a significant impact on the operation of network systems.The IoT and the Internet of Vehicles (IOV) [9] are already in the air, and they're both here to remain. Everywhere in the globe, there's been some kind of implementation of this principle up to this point.

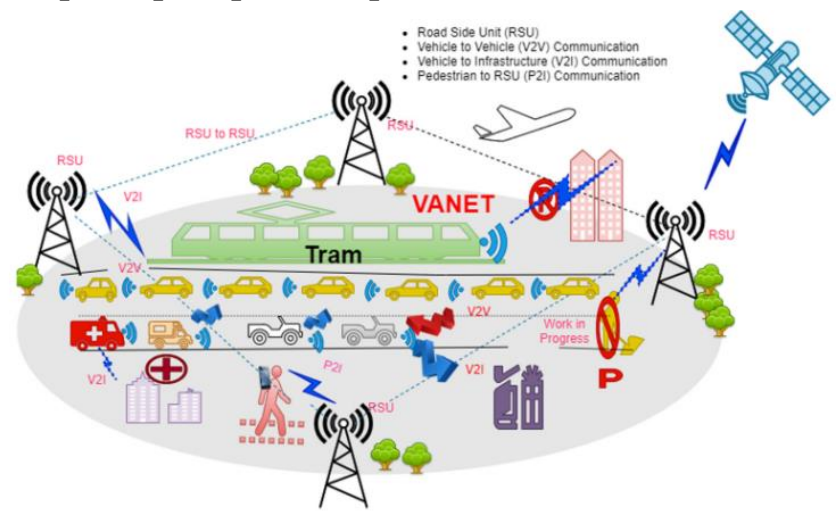

Figure 1. V2X interaction is shown in a simplified depiction of VANET

$\mathrm{V}$ signifies on-road vehicles, whereas $\mathrm{X}$ denotes everything else - RSUs, trams, buildings, pedestrians, and other vehicles, to name a few.

Unawareness of one's surroundings is the biggest cause of road deaths. VANETs provide a variety of solutions to problems such as traffic congestion, fatalities, and emergencies. A VANET is a subclass of MANET. It is a decentralized, architecture-free, ad hoc network that is utilized in V2X interaction. Fig. 1 summarizes the VANET road scenario. Vehicles communicate with people, trams, buildings, traffic signals, and other permanent architecture in this scenario, demonstrating the use of V2X communication.

\section{A. VANET Characteristics}


The following is a list of VANET features[10]:

- Predictable node movement

- Large scale network (high vehicle density)

- Hard delay constraints

- No power constraints

- Limited lifetime for communication links

- High mobility, Dynamic topology

\section{B. VANET Challenges}

There are, however, a slew of issues with VANETs, as outlined under[10]:

- Signal Fading

- Connectivity

- Time Constraints

- Limited Bandwidth

- Routing Protocols

- Security/Attacks/Threats

- Emergency Messages

\section{Data Dissemination in VANETs}

VANETs are a potential class of networks that enable $\mathrm{V} 2 \mathrm{~V}$ communication to promote safe and efficient transportation. Vehicles may connect with and with other networks throughout the trips by engaging with them and with the mobile phone network. Data dissemination is basic activity needed by a wide variety of services in VANETs, and it entails the distribution of data messages to a group of vehicles. Knowledge of the interactions between vehicles may aid in improving the efficacy of data distribution in this sort of communication. [11].

\section{Concept of Clustering in VANET}

Due to the complex communications environment, VANETs have not yet been widely used in the real world. It is especially difficult for VANETs to deal with the hidden node issue because of their low bandwidth and extremely changeable channel, which is affected by both fixed \& mobile obstacles and interference. An infrastructure-based network has a considerable benefit over ad hoc networks in this scenario: access points enable efficient channel scheduling \& dispersal of network resources in a very straightforward way, at the expense of required to construct a high no. of access points across targeted coverage region. Clusterin VANETs, where a hierarchy network architecture is disseminated across the networks by a certain form of clusters method, has been studied by researchers to attain some of the advantages of an infrastructure-based network withoutthe requirement of actual architecture[12].

\section{A. Taxonomy of VANET Clustering Techniques}

As an outcome of the unique mobility and channel dynamics of the VANET environment, constructing clustering architecture is challenging. It is necessary to start by gathering info about its close neighbors to determine possible cluster heads. Mobility, signal quality, \&capacity to deliver specialized traffic and infotainment services are all factors to consider when choosing a head unit. There are a variety of ways to represent this criterion, including a scalar indicating its suitability for the post of cluster head, Alternatively, the method will announce its appointment when a certain time has elapsed. In furthermore, a node may join a cluster in a variety of ways, and a cluster head supervises its members \& chooses whether or not the cluster must be disbanded or united with another cluster. In this part, we'll go through the many ways we've tried to solve these issues. Using the VANET environment, the pros and cons of each strategy are discussed. Additionally, a discussion is offered on how to increase the applicability of unfavorable techniques to vehicle networks.

\section{1) Cluster Head Selection Strategy}

A CH (Cluster Head) is chosen using a particular algorithm and set of parameters, both of which are detailed in this section. There are three primary evaluation procedures identified:

- precedence

- timers 
- weighted network metrics

Each of these algorithms examines numerous network factors to choose the node that is best suited to serve as $\mathrm{CH}$.

\section{2) Passive Clustering}

Clustering algorithms based on weighted metrics, precedence, and timers all have the property of being active. That is, they share a shared channel with other network traffic for cluster formation \& maintenance. Even though clustering is intended to enhance routing, this may lead to a conflict among clusters \& routing traffic, as both compete for restricted channels capability. The benefit of passive approaches is that they avoid conflict between clustering and traffic routing, enabling the former to aid the latter in accomplishing its aim. Due to added management overhead necessary for cluster creation and reformation, an active clustering technique may dramatically impair the efficacy of an ad hoc routing protocol. By contrast, passive techniques make use of the synergy among2schemes to facilitate cluster formation without requiring additional traffic.

\section{3) Cluster Head selection Criteria}

The criteria utilized to select possible $\mathrm{CHs}$ are often established to reduce the detrimental impacts of mobility on interaction reliability \& throughput, application efficiency, or both. The first VANET clustering algorithms were expansions of MANET methods like LID/HD, DMAC [13], or MOBIC. VANET study is gradually moving toward novel $\mathrm{CH}$ selection criteria that make clusters more resilient to variations in topology. Numerous newly suggested techniques include the following:

- signal quality indicators

- node mobility parameters

- platoon leadership

- link expiration time

- trustworthiness

- driver intention
- vehicle class

\section{4) Cluster Member Affiliation Strategy}

Once a node has discovered its intended $\mathrm{CH}$, it will transmita joining request message to prospective $\mathrm{CH}$ unless it decides to accept the role itself. Upon receipt \& approval by the $\mathrm{CH}$, the identification token of requesting node, including its MAC addresses, will be entered into the cluster table. That's where most of the methods analyzed will come to an end, although some will send a verification frame to CM (Cluster Member) alerting it of either success or failure. Among methods, this handshake is crucial since it leads to a no. of major advantages \& disadvantages, which are discussed in further depth below.

- Increased Overhead

- Cluster Control Capability

- Improved Integrity

\section{5) Neighborhood Discovery}

In the architecture of VANET clusters, two approaches for neighborhood finding are utilized. Every node or just those nodes who have declared themselves to be $\mathrm{CH}$ may broadcast periodic hello messages, as in MDMAC [14] or timer-based schemes like CBLR [15]. A node transmits an Inquiry frame to other nodes \& waits for a reaction; this is a poll of local network topology. As a result, identifying a neighbor might be proactive or reactive, as in the instance of Hello broadcasts or Inquire requests.

\section{6) Gateway selection Metrics}

Numerous techniques covered in this article make use of clustering to facilitate routing \&combinationamong cellular networks \& VANETs. For the sake of connecting to other clusters, these algorithms classifythe most appropriate cluster member (CM), which is not usually the $\mathrm{CH}$. Requirements are frequently particular to a certain operation. A gateway node's confidence level must be high 
sufficient to resist a malicious node's attack for routing protocol developed for security apps to qualify as gateway nodes.

\section{7) Cluster Maintenance}

After a cluster is created, $\mathrm{CH}$ is responsible for managing communication among members and ensuring the cluster's topology remains stable. As previously stated, [16], both the road network configuration \& vehicle density have a significant impact on cluster stability. To successfully preserve a cluster's stability,

the $\mathrm{CH}$ shouldvigorouslypreservethe database of its members and react promptly to membership changes. The literature describes two primary database update techniques; these, as well as probable reasons of instability \& recommended mitigation measures, are discussed in the following sections.
- Merging Clusters

- CM Data Updates

- $\mathrm{CH}$ Depreciation

The decision to take clustering factors into account for $\mathrm{CH}$ selection, $\mathrm{CM}$ selection, \& cluster management has been made based on a variety of applications. Multiple parameters have been employed in the clustering method in recent years at various stages. The full image of the networking research landscape's many aspects has been depicted by a few prominent works. The section contains typical papers that included clustering parameters into suggested algorithms to determine the extent of this study. In Table I, we summarize these prior efforts, emphasizing the classes with the highest delegate distributions.

Table I. Clustering variables utilized in suggested methods are compared in this overview

\begin{tabular}{|l|l|l|l|l|l|}
\hline $\begin{array}{l}\text { Authors \& } \\
\text { publication }\end{array}$ & Summary & $\begin{array}{l}\text { No. of } \\
\text { parameters }\end{array}$ & Purposes & Simulator & Problems \\
\hline $\begin{array}{l}\text { I. Nikolaidis, P. } \\
\text { Gburzynski\&E. } \\
\text { Souza (in } \\
\text { IEEE)[17] }\end{array}$ & $\begin{array}{l}\text { Using Beacon- } \\
\text { based } \\
\text { communicatio } \\
\text { ns to extend } \\
\text { the lifespan of } \\
\text { the cluster }\end{array}$ & 1 & $\begin{array}{l}\text { Cluster lifetime } \\
\text { has been } \\
\text { extended. } \\
\text { The network will } \\
\text { be more stable. } \\
\text { Calculations } \\
\text { depend } \\
\text { on weight. }\end{array}$ & $\begin{array}{l}\text { SUMO/S } \\
\text { MURPH }\end{array}$ & $\begin{array}{l}\text { If CHs are in close } \\
\text { proximity, } \\
\text { messages will be } \\
\text { overlapping. } \\
\text { The chances of a } \\
\text { crash are higher. } \\
\text { Simulated results } \\
\text { are based on one- } \\
\text { way data. } \\
\text { There is no } \\
\text { discussion of re- } \\
\text { clustering latency }\end{array}$ \\
\hline $\begin{array}{l}\text { K. Lu, D. Jia, X. } \\
\text { Zhang, J. } \\
\text { Wang\& X. } \\
\text { Shen (in IEEE) } \\
{[18]}\end{array}$ & $\begin{array}{l}\text { In platooning } \\
\text { \& clustering, } \\
\text { there is a } \\
\text { correlation } \\
\text { between } \\
\text { traffic }\end{array}$ & 2 & $\begin{array}{l}\text { Cluster lifetime } \\
\text { has been } \\
\text { extended. } \\
\text { The network will } \\
\text { be more stable. } \\
\text { Calculations }\end{array}$ & $\begin{array}{l}\text { Matlab/ } \\
\text { Simulink, } \\
\text { SUMO/V } \\
\text { eins }\end{array}$ & $\begin{array}{l}\text { Dynamics of } \\
\text { traffic. The } \\
\text { architecture of a } \\
\text { network. }\end{array}$ \\
\hline
\end{tabular}




\begin{tabular}{|c|c|c|c|c|c|}
\hline & $\begin{array}{l}\text { dynamics \& } \\
\text { VANET } \\
\text { behavior }\end{array}$ & & $\begin{array}{l}\text { depend } \\
\text { on weight. }\end{array}$ & & \\
\hline $\begin{array}{l}\text { S. C. Ergen, O. } \\
\text { Ozkasap\&S. } \\
\text { Ucar (in IEEE } \\
\text { Transactions) [1 } \\
\text { 9] }\end{array}$ & $\begin{array}{l}\text { At the lowest } \\
\text { level of } \\
\text { cellular } \\
\text { design, a } \\
\text { technique for } \\
\text { stable } \\
\text { clustered } \\
\text { vehicular } \\
\text { multihop has } \\
\text { been } \\
\text { presented. }\end{array}$ & 2 & $\begin{array}{l}\text { Connectivity to } \\
\text { the Network. } \\
\text { An issue with } \\
\text { broadcast storms. }\end{array}$ & $\begin{array}{l}\text { Sumo/NS- } \\
3\end{array}$ & $\begin{array}{l}\text { High cost of using } \\
\text { cellular design }\end{array}$ \\
\hline $\begin{array}{l}\text { D. Franklin, C. } \\
\text { Cooper, F. } \\
\text { Safaei, M. } \\
\text { Abolhasan\&M. } \\
\text { Ros (in IEEE } \\
\text { Communicatio } \\
n s) \text { [12] }\end{array}$ & $\begin{array}{l}\text { clustering } \\
\text { methods: a } \\
\text { complete } \\
\text { review }\end{array}$ & 2 & $\begin{array}{l}\text { The absence of } \\
\text { realistic channel } \\
\text { modeling for } \\
\text { clustering } \\
\text { efficiency has } \\
\text { been discovered. } \\
\text { Tackle the issues } \\
\text { of dependability } \\
\text { \& scalability in } \\
\text { urban } \\
\text { environments. } \\
\text { Congestion } \\
\text { detection is } \\
\text { enhanced. }\end{array}$ & $\begin{array}{l}\text { Not } \\
\text { simulated }\end{array}$ & $\begin{array}{l}\text { The lack of } \\
\text { technological } \\
\text { implementation }\end{array}$ \\
\hline $\begin{array}{l}\text { B. Hassanabadi, } \\
\text { S. Valaee\&C. } \\
\text { Shea (in } \\
I E E E)[20]\end{array}$ & $\begin{array}{l}\text { A framework } \\
\text { of cluster } \\
\text { structure in } \\
\text { which } \\
\text { mobility plays } \\
\text { a crucial role }\end{array}$ & 2 & $\begin{array}{l}\text { Clusters alter less } \\
\text { often now } \\
\text { because there are } \\
\text { fewer members. }\end{array}$ & NS-2 & $\begin{array}{l}\text { The method's } \\
\text { efficiency suffers } \\
\text { because of a lossy } \\
\text { channel. }\end{array}$ \\
\hline $\begin{array}{l}\text { J. Kang, D. Lin, } \\
\text { Y. Wu, A. } \\
\text { Squicciarini, O. } \\
\text { Tonguzand S. } \\
\text { Gurung } \\
\text { (in IEEE }\end{array}$ & $\begin{array}{l}\text { Using a } \\
\text { moving zone- } \\
\text { based design, } \\
\text { mobile nodes } \\
\text { can share info } \\
\text { more easily }\end{array}$ & 2 & $\begin{array}{l}\text { Pure V2V } \\
\text { interaction } \\
\text { without the need } \\
\text { for frequent } \\
\text { changes and with } \\
\text { fewer resources. }\end{array}$ & $\begin{array}{l}\text { NS- } \\
\text { 2/SUMO }\end{array}$ & $\begin{array}{l}\text { There is no } \\
\text { consideration for } \\
\text { channel modeling }\end{array}$ \\
\hline
\end{tabular}




\begin{tabular}{|c|c|c|c|c|c|}
\hline $\begin{array}{l}\text { Transactions) } \\
{[21]}\end{array}$ & & & $\begin{array}{l}\text { Stable clusters } \\
\text { are a good } \\
\text { approach for } \\
\text { routing. }\end{array}$ & & \\
\hline $\begin{array}{l}\text { S. Olariu, M. C. } \\
\text { Weigle\&M. S. } \\
\text { Almalag(in } \\
I E E E)[22]\end{array}$ & $\begin{array}{l}\text { TDMA slot } \\
\text { allocation } \\
\text { depending on } \\
\text { vehicle } \\
\text { clustering }\end{array}$ & 2 & $\begin{array}{l}\text { Inter-cluster } \\
\text { interaction that } \\
\text { does not interfere } \\
\text { with each other. } \\
\text { Use of the fare } \\
\text { channels. } \\
\text { Decrease the } \\
\text { terminal issue. } \\
\text { Non-safety } \\
\text { communications } \\
\text { may be sent } \\
\text { without affecting } \\
\text { the safety } \\
\text { messages being } \\
\text { sent }\end{array}$ & NS-3 & $\begin{array}{l}\text { When the flow } \\
\text { rate is raised, the } \\
\text { density rises, and } \\
\text { the likelihood of a } \\
\text { crash increases }\end{array}$ \\
\hline $\begin{array}{l}\text { W. Zhang, Y. } \\
\text { Hu,Y. Luo (in } \\
\text { IEEE) [23] }\end{array}$ & $\begin{array}{l}\text { Realtime apps } \\
\text { need cluster- } \\
\text { based routing }\end{array}$ & 2 & $\begin{array}{l}\text { An ideal cluster } \\
\text { of neighbors' } \\
\text { info. } \\
\text { Delay from } \\
\text { beginning to } \\
\text { finish is about } \\
\text { average. } \\
\text { Lowered costs \& } \\
\text { delays in packet } \\
\text { delivery. } \\
\text { Improved PDR \& } \\
\text { reduced caching } \\
\text { memory use. }\end{array}$ & NCTUns & $\begin{array}{l}\text { It doesn't find any } \\
\text { new routes. } \\
\text { There is no way to } \\
\text { access a stored } \\
\text { route }\end{array}$ \\
\hline $\begin{array}{l}\text { Hang Su, \& Xi } \\
\text { Zhang, } \\
\text { (in IEEE } \\
\text { Transactions) }[2 \\
4]\end{array}$ & $\begin{array}{l}\text { Delivering } \\
\text { Public Safety } \\
\text { Messages } \\
\text { through } \\
\text { Multi- } \\
\text { Channel } \\
\text { Cluster }\end{array}$ & 3 & $\begin{array}{l}\text { QoS. } \\
\text { Decrease the } \\
\text { amount of data } \\
\text { congestion }\end{array}$ & Matlab & $\begin{array}{l}\text { Only V2V } \\
\text { interaction is the } \\
\text { focus of this } \\
\text { project. } \\
\text { Broadcast storms } \\
\text { will be exacerbated } \\
\text { by this medium's } \\
\text { inherent nature. }\end{array}$ \\
\hline
\end{tabular}




\begin{tabular}{|c|c|c|c|c|c|}
\hline $\begin{array}{l}\text { A. Benslimane, } \\
\text { T. Taleb and R. } \\
\text { Sivaraj (in IEEE } \\
\text { Journal)[25] }\end{array}$ & $\begin{array}{l}\text { An adaptive } \\
\text { gateway } \\
\text { management } \\
\text { system that } \\
\text { serves } \\
\text { gateway } \\
\text { migrations \& } \\
\text { discovery, } \\
\text { advertising, } \\
\text { and gateway } \\
\text { apps. }\end{array}$ & 3 & $\begin{array}{l}\text { Due to proactive } \\
\text { routing, there } \\
\text { was a decrease in } \\
\text { latency. } \\
\text { Signaling } \\
\text { overhead is } \\
\text { reduced. }\end{array}$ & NS-2 & $\begin{array}{l}\text { Use of } 3 G \text { cellular } \\
\text { phone technology. } \\
\text { Fixed routing table. } \\
\text { Network } \\
\text { connection may be } \\
\text { affected by sudden } \\
\text { changes in } \\
\text { topology. }\end{array}$ \\
\hline $\begin{array}{l}\text { M. Khabazian } \\
\text { and M. K. M. } \\
\text { Ali (in IEEE } \\
\text { Transactions) } \\
\text { [26] }\end{array}$ & $\begin{array}{l}\text { The impact of } \\
\text { VANET } \\
\text { mobility on } \\
\text { the network's } \\
\text { connection }\end{array}$ & 3 & $\begin{array}{l}\text { Reduce traffic } \\
\text { jams that ensure } \\
\text { deadlock on the } \\
\text { highway }\end{array}$ & Matlab & $\begin{array}{l}\text { There was just one- } \\
\text { way traffic. } \\
\text { Only the number } \\
\text { of lanes was } \\
\text { considered in the } \\
\text { study. }\end{array}$ \\
\hline $\begin{array}{l}\text { S. Dornbush } \\
\text { and A. Joshi (in } \\
\text { IEEE) [27] }\end{array}$ & $\begin{array}{l}\text { This article } \\
\text { evaluates the } \\
\text { use of mobile } \\
\text { peer-to-peer } \\
\text { networks to } \\
\text { monitor } \\
\text { vehicle traffic } \\
\text { flow }\end{array}$ & 3 & $\begin{array}{l}\text { Offered traffic } \\
\text { dynamics to } \\
\text { alleviate traffic } \\
\text { jams \& } \\
\text { congestion. } \\
\text { As there are no } \\
\text { issues with } \\
\text { electricity, it } \\
\text { saves gasoline \& } \\
\text { resources. } \\
\text { The size \& cost of } \\
\text { a node is not } \\
\text { constrained. }\end{array}$ & Tiger data & $\begin{array}{l}\text { Dynamic network } \\
\text { with few } \\
\text { connections. } \\
\text { There are issues } \\
\text { with the road map. }\end{array}$ \\
\hline $\begin{array}{l}\text { L. Bononi and } \\
\text { M. di Felice (in } \\
\text { IEEE) [28] }\end{array}$ & $\begin{array}{l}\text { A multi-hop } \\
\text { MAC forward } \\
\text { cross-layered } \\
\text { technique to } \\
\text { dynamically } \\
\text { create virtual } \\
\text { backbone } \\
\text { architecture }\end{array}$ & 3 & $\begin{array}{l}\text { It's cost-effective. } \\
\text { Time-saving }\end{array}$ & NS-2 & $\begin{array}{l}\text { Due to a large shift } \\
\text { in topography, the } \\
\text { link among the } \\
\text { vehicles could be } \\
\text { disrupted. }\end{array}$ \\
\hline
\end{tabular}




\begin{tabular}{|c|c|c|c|c|c|}
\hline $\begin{array}{l}\text { A. Benslimane, } \\
\text { K. B. } \\
\text { Letaief\&T. } \\
\text { Taleb (in IEEE } \\
\text { Transactions) } \\
{[29]}\end{array}$ & $\begin{array}{l}\text { The } \\
\text { introduction } \\
\text { of a } \\
\text { cooperative } \\
\text { crash method } \\
\text { in the event of } \\
\text { a flood was } \\
\text { done to } \\
\text { prevent it. }\end{array}$ & 3 & $\begin{array}{l}\text { Broadcasts are } \\
\text { less redundant. } \\
\text { Packet loss has } \\
\text { been reduced. }\end{array}$ & NS-2 & $\begin{array}{l}\text { Doesn't take into } \\
\text { account the } \\
\text { broadcast storm. }\end{array}$ \\
\hline $\begin{array}{l}\text { N. Tabbane, G. } \\
\text { e. m. Zhioua, S. } \\
\text { Tabbane\&H. } \\
\text { Labiod } \\
\text { (in IEEE } \\
\text { Transactions)[3 } \\
\text { 0] }\end{array}$ & $\begin{array}{l}\text { A multi- } \\
\text { metric } \\
\text { deterministic } \\
\text { approach to } \\
\text { selecting } \\
\text { gateways in } \\
\text { clustering }\end{array}$ & 3 & $\begin{array}{l}\text { There will be no } \\
\text { inter-cluster } \\
\text { communications } \\
\text { collisions. } \\
\text { Hops in a single } \\
\text { group. }\end{array}$ & NS-2 & $\begin{array}{l}\text { Broadcast a safety } \\
\text { message. } \\
\text { Non-realistic due } \\
\text { to the premise of } \\
\text { no collision. } \\
\text { Intensified stress } \\
\text { on the CH. } \\
\text { Packet loss is high. } \\
\text { End-to-end latency } \\
\text { has been enhanced. }\end{array}$ \\
\hline $\begin{array}{l}\text { B. Wiegel, H. } \\
\text { P. } \\
\text { Grossmann\&Y. } \\
\text { Gunter (in } \\
\text { IEEE) [31] }\end{array}$ & $\begin{array}{l}\text { according to } \\
\text { Medium } \\
\text { Access } \\
\text { Protocol } \\
\text { (MAPP) }\end{array}$ & 3 & $\begin{array}{l}\text { Reduce the } \\
\text { concealed } \\
\text { terminal issue. } \\
\text { Scalability. } \\
\text { Enhanced quality } \\
\text { of } \\
\text { service. decrease } \\
\text { d Overhead }\end{array}$ & Unknown & $\begin{array}{l}\text { The greatest } \\
\text { number of nodes } \\
\text { that may be used in } \\
\text { a simulation is } 100 \text {. } \\
\text { In the event of a } \\
\text { flood, Hello } \\
\text { messages might be } \\
\text { the culprit. } \\
\text { Increasing no. of } \\
\text { nodes reduces the } \\
\text { success rate of } \\
\text { packet } \\
\text { transmissions }\end{array}$ \\
\hline $\begin{array}{l}\text { S. Senouci, G. } \\
\text { Remy, Y. } \\
\text { Gourhant\&F. } \\
\text { Jan (in IEEE) } \\
\text { [32] }\end{array}$ & $\begin{array}{l}\text { Using LTE as a } \\
\text { central } \\
\text { vehicle } \\
\text { network } \\
\text { organization }\end{array}$ & 4 & $\begin{array}{l}\text { Cluster efficiency } \\
\text { may be } \\
\text { improved. Low } \\
\text { overhead Preve } \\
\text { nt CH from } \\
\text { experiencing an } \\
\text { early loss of } \\
\text { energy. }\end{array}$ & NS-3 & $\begin{array}{l}\text { If a central system } \\
\text { fails, a deadlock } \\
\text { occurs. There is no } \\
\text { thought given to } \\
\text { security concerns. }\end{array}$ \\
\hline
\end{tabular}




\begin{tabular}{|c|c|c|c|c|c|}
\hline $\begin{array}{l}\text { K. Ibrahim and } \\
\text { M. C. Weigle } \\
\text { (in } \\
\text { IEEE workshop } \\
\text { ) [33] }\end{array}$ & $\begin{array}{l}\text { A method for } \\
\text { integrating } \\
\text { data from } \\
\text { many } \\
\text { sources CASC } \\
\text { ADE was used } \\
\text { to provide } \\
\text { early traffic } \\
\text { congestion } \\
\text { warnings in a } \\
\text { congested } \\
\text { network using } \\
\text { a single frame }\end{array}$ & 4 & $\begin{array}{l}\text { Optimal use of } \\
\text { available wifi } \\
\text { channels. } \\
\text { Information may } \\
\text { be disseminated } \\
\text { more widely. }\end{array}$ & $\mathrm{ASH}$ & $\begin{array}{l}\text { Wi-Fi channel use } \\
\text { that is both } \\
\text { effective and } \\
\text { economical. Data } \\
\text { may be sent across } \\
\text { a larger region. }\end{array}$ \\
\hline $\begin{array}{l}\text { M. Slavik and I. } \\
\text { Mahgoub } \\
\text { (in IEEE } \\
\text { Transactions) } \\
{[34]}\end{array}$ & $\begin{array}{l}\text { Spread multi- } \\
\text { hop wireless } \\
\text { transmissions } \\
\text { for optimal } \\
\text { routing }\end{array}$ & 6 & $\begin{array}{l}\text { Less bandwidth } \\
\text { use and more } \\
\text { coverage }\end{array}$ & $\begin{array}{l}\text { JiST/SWA } \\
\text { NS }\end{array}$ & $\begin{array}{l}\text { Single threshold } \\
\text { value performs } \\
\text { well in all cases, } \\
\text { regardless of the } \\
\text { threshold value }\end{array}$ \\
\hline
\end{tabular}

\section{Literature Survey}

Studies have made tremendous progress in structure \& designing, but there are still regions for development, as the widespread use of VANET infrastructures \& procedures that are both scalable, dependable, resilient \& secure. With these considerations in mind, researchers focused on security vulnerabilities to automobile ad-hoc networks \& suggested different solutions. There were additional security problems that were explored in this investigation.

Certain recent research that does not depend on beacon information transmits a large number of data packets, hence increasing bandwidth wastage. A method is known as the Fuzzy-based Beaconless Probability Broadcasting Algorithm (FBBPA) [36] was created to overcome these issues and alert automobiles of an occurrence with the minimal broadcast. For broadcasting suppressing, this is a receiver-oriented strategy that determines the forwarding probabilities of packets in the vehicles' buffers based on their distances, angular orientation, and movements path. The packet is then rescheduled based on the resulting likelihood. At the moment of transmitting, the most important packets in the vehicle's buffer will be sent first. The examination of accident and advertising packets demonstrates that the suggested approach outperforms in words of reachability (Info coverage), average delay, \& saved rebroadcasts, the tested procedures were assessed.

The research [37] proposes dynamic grouping using $\mathrm{K}$-implies, which is ideally suited for the dynamic topological properties of VANET. The suggested approach performs brilliantly when the number of bunches is specified in advance as well as when the number of groups is unknown. The client can select no. of bunches or lowest no. of groups required for their approach. To select the next group concentration, the group counter is incremented by one for every emphasis until an objective task is accomplished. All of this may be outlined, including 
ideal group leaders and how $\mathrm{CMs} \& \mathrm{CHs}$ communicate with each other.

A method for Internet of Energy in the context of bus-based VANET, such as a street-centric routing system (SCRS), is presented in this work to address the issue of the best route and relaying bus choosing. To begin, [38] presented a multipath routing strategy based on the likelihood of street \& path consistency. The multipath architecture significantly enhances efficiency in words of PDR \& end-to-end latency. Second, to improve packet forwarding, ACO(Ant Colony Optimization)-based clustering method is used to provide a novel relay-bus selection mechanism. Packets are transported to the next forwarding relays via the relay-purpose bus. The findings show that the ACO technique's clustering improves relay-bus choosing by reducing computing costs, end-to-end delay, \& unnecessary beacon signals. As a result, they find that using multipath \& clustering considerably enhances SCRS performance.

[39] proposes a concept for a modern cellular-5G VANET architecture to resolve all past VANET issues and enhance QoS (Quality of Service). To accomplish this, A-MAPS(Adaptive Mobility-Aware Path Similarity) method is used to cluster all vehicles in the area of interest. Cluster formation \& $\mathrm{CH}$ selection are based on several critical characteristics, one of them being the importance of comparable future paths in metropolitan regions. An optimal forwarder for V2V \&D2D communications is found by using a Bayesian rule-based fuzzy logic framework (BRFL) developed by the researchers to provide reliable communication between vehicles \& devices. Additionally, communication between V2I and vehicles to pedestrians (V2P) is handled using a unique2F-HSO (2-Fitness Hypotrochoid Spiral Optimization) method built from fitness functions. Two distinct message kinds (Accident \& Traffic) are examined for safety message dissemination, alsoSAHTD(Safety-Aware Hierarchical Tree for
Dissemination) is created to manage their dissemination. An $\mathrm{OMNeT}_{++}$simulator is used to simulate the planned cellular-5G VANET. The results reveal that transmission delay, PDR, throughput, \& dissemination delay have all improved.

[40] presented a V2V cooperative video alert distribution technique for broadcasting accident footage in an IoVs highway scenario. A cooperative two-way transmission technique is developed. Clustering of cars traveling in the same route as the incident vehicle form \& communicate inside clustering, while vehicles traveling in the opposite direction choose to relay vehicles to aid in delivering video swiftly \& reliably.Problems posed by the features of IoVs are overcome by careful consideration of many parameters throughout the mechanism's design, Vehicle speeds, positions, distances, channels conditions, \& data reception statuses are all included. Additionally, to account for the efficiency loss caused by the heterogeneity of automobiles in different locations, SVC (Scalable Video Coding) technology is used to encode the actual accident video. During cooperative transmissions, Instantly Decodable Network Coding (IDNC) is used to further improve the transmission efficiency and reliability of the information. The simulation outcomes demonstrate that the suggested approach efficiently reduces the latency in transmitting accident video, boosts the success warning ratio, improves the quality of rebuilding video, \& increases user satisfaction.

OEE-SEP method for IoV in smart cities was introduced in [41] for vehicle activity discharges in the predicted time and with the lowest amount of energy consumption. Both undirected \& similar activity discharge procedures are included in the sensible edge processing framework, which differs by no. of duties completed per unit time \& projected time necessary to finish a similar amount of data input. An energy-efficient method is created to 
decrease total communication delays \& the amount of energy used during discharging. IoV procedures \& data loading activity are handled by OEE-SEP, which reduces activity discharge energy use. With shorter communications delays\& less energy consumption, testing outcomesdemonstrate that the proposed approach improvesthe efficiency rate of vehicle automated systems in smart cities by $97.55 \%$.

This study [42] offered a novel way for achieving quick and reliable data transfer by using machine learning techniques for data processing to boost the speed and security of vehicular network data transmission. The suggested system utilizes a 5G cellular network in conjunction with alternate data transmission mechanisms. The study is innovative in that it considers a variety of traffic circumstances (the amount to which roads are congested might impact the quality of big data transmission) and proposes a method for improving big data transmission via the use of SVM Classifier technology. The study's findings indicate that the proposed technique is sufficiently successful with huge data and may be used to enhance the performance and security of urban VANET networks. The study's findings may aid in the development of high-performance 5G-VANET applications aimed at enhancing traffic safety in urban vehicle environments.

Table II. Comparison of MAC methods on a qualitative level

\begin{tabular}{|l|l|l|l|}
\hline Parameters & $\begin{array}{l}\text { IEEE } \\
\mathbf{8 0 2 . 1 1} \\
\text { MAC }\end{array}$ & $\begin{array}{l}\text { AD- } \\
\text { HOC } \\
\text { MAC }\end{array}$ & Ve-MAC \\
\hline Type & CSMA/CA & $\begin{array}{l}\text { RRAL } \\
\text { OHA }\end{array}$ & TDMA \\
\hline $\begin{array}{l}\text { Time } \\
\text { Synchroniza } \\
\text { tion }\end{array}$ & $\begin{array}{l}\text { Not } \\
\text { Required }\end{array}$ & $\begin{array}{l}\text { Requir } \\
\text { ed }\end{array}$ & Required \\
\hline Mobility & Medium to & Mediu & High \\
\hline
\end{tabular}

\begin{tabular}{|l|l|l|l|}
\hline & High & $\mathrm{m}$ & \\
\hline $\begin{array}{l}\text { Hidden } \\
\text { Terminal } \\
\text { Problem }\end{array}$ & Yes & No & No \\
\hline Reliability & No & Yes & Yes \\
\hline $\begin{array}{l}\text { Multi- } \\
\text { channel } \\
\text { support }\end{array}$ & Yes & No & Yes \\
\hline $\begin{array}{l}\text { High } \\
\text { Density of } \\
\text { traffic }\end{array}$ & Yes & No & Yes \\
\hline $\begin{array}{l}\text { Channel } \\
\text { Utilization }\end{array}$ & Limited & Low & High \\
\hline $\begin{array}{l}\text { Throughput } \\
\text { Medium }\end{array}$ & $\begin{array}{l}\text { Mediu } \\
\mathrm{m}\end{array}$ & High \\
\hline
\end{tabular}

The following table compares Ve-MAC to various MAC protocols, including AD-HOC MAC and IEEE 802.11 MAC. While the Ve-MAC protocol performs improved even as vehicle density grows, IEEE 802.11 \& AD HOC MAC protocols' dependability reductions as vehicle density grow, resulting in efficiency degradation in urban environments. Second, IEEE802.11 and Ve-MAC enable high vehicle mobility, whereas AD-HOC MAC does not. Ad Hoc MAC has an excellent QoS(Quality of Service), but IEEE 802.11 is not real-time owing to its higher delay, which outcomes in a worse QoS.

\section{Conclusion}

VANET is a new vehicle technology for ITS that minimizes collisions by transmitting safety messages between vehicles. VANETs are a new technology that will become more integrated in the next years. This poll found that further research is required to improve the VANET infrastructure. There is a requirement for performance assessment of the protocols used for routing in VANETs. Certain methodologies, procedures, and systems discussed in related work lack simulation findings. The primary approach presented is clustering, along with a 
comparison of many suggested algorithms based on various parameters. Certain factors, such as QoS, credibility, trust prototype assessment, \& scalability, must be efficiently computed or assessed. One of the most significant issues facing VANETs is the need to optimize response time. While the study conducted so far is adequate, as technology becomes more demanding regularly, VANET implementation should consider every area of security, efficiency, low energy consumption, reliability, and robustness. As the dependability of the safety message improves, performance improves significantly.

Future studies may involve the examination of routing methods and the establishment of connectivity in isolated environments. The study of hybrid communication schemes demonstrates how the connection may be achieved in both dense \& sparse traffic situations.

\section{REFERENCES}

[1]. M. S. Devi and K. Malar, "Improved Performance Modeling of Intelligent Safety Message Broadcast in Vanet: A Survey," in 2014 International Conference on Intelligent Computing Applications, 2014, pp. 95-98, doi: 10.1109/ICICA.2014.29.

[2]. Y. Yao, K. Zhang, and X. Zhou, "A Flexible Multi-Channel Coordination MAC Protocol for Vehicular Ad Hoc Networks," IEEE Commun. Lett., vol. 21, no. 6, pp. 1305-1308, 2017, doi: 10.1109/LCOMM.2017.2681060.

[3]. Z. Peng, S. Gao, Z. Li, B. Xiao, and Y. Qian, "Vehicle Safety Improvement through Deep Learning and Mobile Sensing," IEEE Netw., vol. 32, no. 4, pp. 28-33, 2018, doi: 10.1109/MNET.2018.1700389.

[4]. J. Tian and F. Meng, "Comparison Survey of Mobility Models in Vehicular Ad-Hoc Network (VANET)," in 2020 IEEE 3rd International Conference on Automation, Electronics and
Electrical Engineering (AUTEEE), 2020, pp. 337342, doi: 10.1109/AUTEEE50969.2020.9315583.

[5]. D. Jiang, V. Taliwal, A. Meier, W. Holfelder, and R. Herrtwich, "Design of 5.9 ghz dsrc-based vehicular safety communication," IEEE Wirel. Commun., vol. 13, no. 5, pp. 36-43, 2006, doi: 10.1109/WC-M.2006.250356.

[6]. R. Al-ani, B. Zhou, Q. Shi, and A. Sagheer, "A Survey on Secure Safety Applications in VANET," in 2018 IEEE 20th International Conference on High Performance Computing and Communications; IEEE 16th International Conference on Smart City; IEEE 4th International Conference on Data Science and Systems (HPCC/SmartCity/DSS), 2018, pp. 14851490 ,

doi: 10.1109/HPCC/SmartCity/DSS.2018.00245.

[7]. A. khan, M. Ishtiaq, S. Anwar, and M. A. Shah, "A Survey on secure routing strategies in VANETs," in 2019 25th International Conference on Automation and Computing (ICAC), 2019, pp. 1-6, doi: 10.23919/IConAC.2019.8895221.

[8]. A. Singh and S. Kad, "A Review on the Various Security Techniques for VANETs," Procedia Comput. Sci., vol. 78, pp. 284-290, 2016, doi: https://doi.org/10.1016/j.procs.2016.02.055.

[9]. S. Sharma and B. Kaushik, "A survey on internet of vehicles: Applications, security issues \& solutions," Veh. Commun., vol. 20, p. 100182, 2019 , doi: https://doi.org/10.1016/j.vehcom.2019.100182.

[10].R. Kaur, R. K. Ramachandran, R. Doss, and L. Pan, "The importance of selecting clustering parameters in VANETs: A survey," Comput. Sci. Rev., vol. 40, p. 100392, 2021, doi: https://doi.org/10.1016/j.cosrev.2021.100392.

[11].L. H. S. Lopes, R. A. F. Mini, and F. Cunha, "A V2X Approach for Data Dissemination in Vehicular Ad Hoc Networks," 2019, doi: 10.1109/ISCC47284.2019.8969698.

[12].C. Cooper, D. Franklin, M. Ros, F. Safaei, and M. Abolhasan, "A Comparative Survey of VANET 
Clustering Techniques," IEEE Commun. Surv. Tutorials, vol. 19, no. 1, pp. 657-681, 2017, doi: 10.1109/COMST.2016.2611524.

[13].S. Basagni, "Distributed clustering for ad hoc networks," in Proceedings Fourth International Symposium on Parallel Architectures, Algorithms, and Networks (I-SPAN'99), 1999, pp. 310-315, doi: 10.1109/ISPAN.1999.778957.

[14].G. Wolny, "Modified DMAC Clustering Algorithm for VANETs," in 2008 Third International Conference on Systems and Networks Communications, 2008, pp. 268-273, doi: 10.1109/ICSNC.2008.28.

[15].R. A. Santos, R. M. Edwards, and A. Edwards, "Cluster-based location routing algorithm for inter-vehicle communication," in IEEE 60th Vehicular Technology Conference, 2004. VTC2004-Fall. 2004, 2004, vol. 2, pp. 914-918 Vol. 2, doi: 10.1109/VETECF.2004.1400154.

[16].C. Cooper, M. Ros, F. Safaei, D. Franklin, and M. Abolhasan, "Simulation of Contrasting Clustering Paradigms under an Experimentally-Derived Channel Model," in 2014 IEEE 80th Vehicular Technology Conference (VTC2014-Fall), 2014, pp. 1-6, doi: 10.1109/VTCFall.2014.6966179.

[17].E. Souza, I. Nikolaidis, and P. Gburzynski, "A New Aggregate Local Mobility (ALM) Clustering Algorithm for VANETs," in 2010 IEEE International Conference on Communications, 2010, pp. 1-5, doi: 10.1109/ICC.2010.5501789.

[18].D. Jia, K. Lu, J. Wang, X. Zhang, and X. Shen, “A Survey on Platoon-Based Vehicular CyberPhysical Systems," IEEE Commun. Surv. Tutorials, vol. 18, no. 1, pp. 263-284, 2016, doi: 10.1109/COMST.2015.2410831.

[19].S. Ucar, S. C. Ergen, and O. Ozkasap, "MultihopCluster-Based IEEE 802.11p and LTE Hybrid Architecture for VANET Safety Message Dissemination," IEEE Trans. Veh. Technol., vol. 65, no. 4, pp. 2621-2636, 2016, doi: 10.1109/TVT.2015.2421277.
[20].C. Shea, B. Hassanabadi, and S. Valaee, "Mobility-Based Clustering in VANETs Using Affinity Propagation," in GLOBECOM 2009 2009 IEEE Global Telecommunications Conference, 2009, pp. 1-6, doi: 10.1109/GLOCOM.2009.5425236.

[21].D. Lin, J. Kang, A. Squicciarini, Y. Wu, S. Gurung, and O. Tonguz, "MoZo: A Moving Zone Based Routing Protocol Using Pure V2V Communication in VANETs," IEEE Trans. Mob. Comput., vol. 16, no. 5, pp. 1357-1370, 2017, doi: 10.1109/TMC.2016.2592915.

[22].M. S. Almalag, S. Olariu, and M. C. Weigle, "TDMA cluster-based MAC for VANETs (TCMAC)," in 2012 IEEE International Symposium on a World of Wireless, Mobile and Multimedia Networks (WoWMoM), 2012, pp. 1-6, doi: 10.1109/WoWMoM.2012.6263796.

[23].Y. Luo, W. Zhang, and Y. Hu, "A new cluster based routing protocol for VANET," Networks Secur. Wirel. Commun. Trust. Comput. Int. Conf., vol. 1, pp. 176-180, 2010, doi: 10.1109/NSWCTC.2010.48.

[24].H. Su and X. Zhang, "Clustering-Based Multichannel MAC Protocols for QoS Provisionings Over Vehicular Ad Hoc Networks," Veh. Technol. IEEE Trans., vol. 56, pp. 3309-3323, 2007, doi: 10.1109/TVT.2007.907233.

[25].A. Benslimane, T. Taleb, and R. Sivaraj, "Dynamic Clustering-Based Adaptive Mobile Gateway Management in Integrated VANET 3G Heterogeneous Wireless Networks," IEEE J. Sel. Areas Commun., vol. 29, no. 3, pp. 559-570, 2011, doi: 10.1109/JSAC.2011.110306.

[26].M. Khabazian and M. K. M. Ali, “A Performance Modeling of Connectivity in Vehicular $<$ emphasis emphistype="italic" $>$ Ad Hoc</emphasis $>$ Networks," IEEE Trans. Veh. Technol., vol. 57, no. 4, pp. 2440-2450, 2008, doi: 10.1109/TVT.2007.912161. 
[27].S. Dornbush and A. Joshi, "StreetSmart Traffic: Discovering and Disseminating Automobile Congestion Using VANET's," in 2007 IEEE 65th Vehicular Technology Conference - VTC2007Spring, 2007, pp. 11-15, doi: 10.1109/VETECS.2007.15.

[28].L. Bononi and M. di Felice, "A Cross Layered MAC and Clustering Scheme for Efficient Broadcast in VANETs," in 2007 IEEE International Conference on Mobile Adhoc and Sensor Systems, 2007, pp. 1-8, doi: 10.1109/MOBHOC.2007.4428735.

[29].T. Taleb, A. Benslimane, and K. Ben Letaief, "Toward an Effective Risk-Conscious and Collaborative Vehicular Collision Avoidance System,” IEEE Trans. Veh. Technol., vol. 59, no. 3, pp. 1474-1486, 2010, doi: 10.1109/TVT.2010.2040639.

[30].G. el mouna Zhioua, N. Tabbane, H. Labiod, and S. Tabbane, "A Fuzzy Multi-Metric QoSBalancing Gateway Selection Algorithm in a Clustered VANET to LTE Advanced Hybrid Cellular Network," IEEE Trans. Veh. Technol., vol. 64, no. 2, pp. 804-817, 2015, doi: 10.1109/TVT.2014.2323693.

[31].Y. Gunter, B. Wiegel, and H. P. Grossmann, "Cluster-based Medium Access Scheme for VANETs," in 2007 IEEE Intelligent Transportation Systems Conference, 2007, pp. 343-348, doi: 10.1109/ITSC.2007.4357651.

[32].G. Remy, S.-M. Senouci, F. Jan, and Y. Gourhant, "LTE4V2X: LTE for a Centralized VANET Organization," in 2011 IEEE Global Telecommunications Conference - GLOBECOM 2011, 2011, pp. 1-6, doi: 10.1109/GLOCOM.2011.6133884.

[33].K. Ibrahim and M. C. Weigle, "CASCADE: Cluster-Based Accurate Syntactic Compression of Aggregated Data in VANETs," in 2008 IEEE Globecom Workshops, 2008, pp. 1-10, doi: 10.1109/GLOCOMW.2008.ECP.59.
[34].M. Slavik and I. Mahgoub, "Spatial Distribution and Channel Quality Adaptive Protocol for Multihop Wireless Broadcast Routing in VANET,” IEEE Trans. Mob. Comput., vol. 12, no. 4, pp. 722-734, 2013, doi: 10.1109/TMC.2012.42.

[35].J. T. Isaac, S. Zeadally, and J. S. Cámara, "Security attacks and solutions for vehicular ad hoc networks," IET Commun., vol. 4, no. 7, pp. 894903, 2010, doi: 10.1049/iet-com.2009.0191.

[36].A. Srivastava, A. Prakash, and R. Tripathi, "Fuzzy-based beaconless probabilistic broadcasting for information dissemination in urban VANET," Ad Hoc Networks, vol. 108, p. 102285, 2020, doi: https://doi.org/10.1016/j.adhoc.2020.102285.

[37].M. Ramalingam and R. Thangarajan, "Mutated kmeans algorithm for dynamic clustering to perform effective and intelligent broadcasting in medical surveillance using selective reliable broadcast protocol in VANET," Comput. Commun., vol. 150, pp. 563-568, 2020, doi: https://doi.org/10.1016/j.comcom.2019.11.023.

[38].Z. Khan, S. Fang, A. Koubaa, P. Fan, F. Abbas, and H. Farman, "Street-centric routing scheme using ant colony optimization-based clustering for bus-based vehicular ad-hoc network," Comput. Electr. Eng., vol. 86, p. 106736, 2020, doi:

https://doi.org/10.1016/j.compeleceng.2020.1067 36.

[39].S. A. Alghamdi, "Novel path similarity aware clustering and safety message dissemination via mobile gateway selection in cellular 5G-based V2X and D2D communication for urban environment," Ad Hoc Networks, vol. 103, p. 102150, 2020, doi: https://doi.org/10.1016/j.adhoc.2020.102150.

[40].S. Wang, Q. Zhang, and G. Chen, "V2V-CoVAD: A vehicle-to-vehicle cooperative video alert dissemination mechanism for Internet of Vehicles in a highway environment," Veh. 
Commun., p. 100418, 2021, doi: https://doi.org/10.1016/j.vehcom.2021.100418.

[41].X. Shen, H. Yu, X. Liu, Q. Bin, A. K. Luhach, and V. Saravanan, "The optimized energy-efficient sensible edge processing model for the internet of vehicles in smart cities," Sustain. Energy Technol. Assessments, vol. 47, p. 101477, 2021, doi: https://doi.org/10.1016/j.seta.2021.101477.

[42].S. Zhang, M. Lagutkina, K. O. Akpinar, and M. Akpinar, "Improving performance and data transmission security in VANETs," Comput. Commun., vol. 180, pp. 126-133, 2021, doi: https://doi.org/10.1016/j.comcom.2021.09.005.

\section{Cite this article as :}

Prashant Kumar Shrivastava, Dr. L. K. Vishwamitra, "Comparison of Different Clustering Algorithms to Secured VANETs Communication", International Journal of Scientific Research in Computer Science, Engineering and Information Technology (IJSRCSEIT), ISSN : 2456-3307, Volume 7 Issue 6, pp. 59-75, November-December 2021. Available at doi : https://doi.org/10.32628/CSEIT217613

Journal URL : https://ijsrcseit.com/CSEIT217613 